\title{
Determination of phenolic compounds in medicinal preparations by galvanostatic coulometry
}

\author{
N.N. Yaschenko*, S.V. Zhitar, E.G. Zinovjeva \\ Chuvash State University, Moskovsky Ave., 15, Cheboksary, Chuvash Republic, Russia \\ * Corresponding author: n.yashenko.n@mail.ru \\ This short communication (letter) belongs to the MOSM2020 Special Issue.
}

(C) 2021, The Authors. This article is published in open access form under the terms and conditions of the Creative Commons Attribution (CC BY) license (http://creativecommons.org/licenses/by/4.o/).

\section{Abstract}

In this work, the possibility of using reactions of electrogenerated titrants with phenolic compounds was studied and a method for their coulometric determination in medicaments by galvanostatic coulometry was developed. The research objects were: rutin, salicylic acid and drugs containing phenolic compounds such as «Ascorutin», «Salicylic Paste» and «Salicylic Ointment» of Russian manufacture. Electrogenerated halogens $\left(\mathrm{Cl}_{2}, \mathrm{Br}_{2}\right.$ and $\left.\mathrm{I}_{2}\right)$ and hexacyanoferrate(III)ions were used as titrants. It was found that for the quantitative determination of phenolic acids, the optimal reagent is electrogenerated bromine, for rutin - electrogenerated bromine and iodine, and for ascorbic acid - any of the studied electrogenerated titrants $\left(\mathrm{Cl}_{2}, \mathrm{Br}_{2}\right.$, $\mathrm{I}_{2}$ and $\left.\left[\mathrm{Fe}(\mathrm{CN})_{6}\right]^{3-}\right)$. The correct definition was checked by the "entered-found» method, the error does not exceed $2 \%$. As experimental studies have shown, our method of coulometric titration with electrogenated bromine and iodine is characterized by good reproducibility of results, expression, accuracy and can be used to determine phenolic compounds in drugs, for example, «Ascorutin» tablets. It should be noted that by our procedure it is possible to determine the spectrum of phenol-containing compounds (rutin, ascorbic and salicylic acids) in drugs without their preliminary separation. Therefore, the coulometric method using electrogenerated titrants can be recommended for the determination of salicylic, ascorbic acids and rutin in dosage forms. The proposed method is accurate and eliminates the experiment error in comparison with the Pharmacopoeic method.

\section{Keywords}

galvanostatic coulometry phenolic compounds

flavonoids

Received: 31.10 .2020

Revised: 25.12 .2020

Accepted: 25.12.2020

Available online: 13.04 .2021

\section{Introduction}

The phenolic group is found in the structure of many medicinal substances and largely determines their pharmacological, physicochemical and chemical properties. Quality control of such medicinal substances requires the determination of indicators characterizing phenolic function. This makes it necessary to study the reactivity and methods of chemical analysis of drugs from the class of phenols.

The guarantee of the effectiveness and safety of medicines is the creation of national standards for their quality. In order to establish the conformity of the quality of medicines to the regulated requirements, it is necessary to use various analytical methods. The conclusion about the quality of drugs depends to a large extent on the quality of the method itself. Therefore, it is necessary to evaluate the suitability of analytical methods for their intended use. However, the State Pharmacopoeia [1] does not always offer the most reliable method for determining the active ingredient in the dosage form.

One of the promising methods of quantifying biologically active compounds is the galvanostatic coulometry method [2], characterized by simplicity of the experiment, expressiveness, high accuracy, lack of expensive equipment and use in a conventional control and analytical laboratory. The purpose of this work is to study the possibility of using reactions of electrogenerated titrants with phenolic compounds and to develop a reliable method for their coulometric determination in drugs. 


\section{Results and Discussion}

The objects of the study were: rutin - as a representative of the class of flavonoids and polyphenols; salicylic acid as a representative of phenolic acids and drugs containing phenolic compounds such as «Ascorutin», "Salicylic Paste» and «Salicylic Ointmen». The titrants used were electrogenated halogens $\left(\mathrm{Cl}_{2}, \mathrm{Br}_{2}\right.$ and $\left.\mathrm{I}_{2}\right)$ and hexacyanoferrate(III)-ions. Generation was carried out at a constant current strength of $I=10 \mathrm{~mA}$, and the equivalence point was fixed biamperometrically with two polarized electrodes on the coulometric analyzer «Expert-006». The selected halogens are not only capable of oxidizing phenolic compounds, but also enter into electrophilic substitution reactions of the benzene ring, while the hexacyanoferrate(III)-ions $\left[\mathrm{Fe}(\mathrm{CN})_{6}\right]^{3-}$ are mild oxidizing agents.

Based on the studies, we found that the electrogenated hexacyanoferrate(III)-ion and electrogenated iodine enter into redox reactions, but since the redox potential $(0.356 \mathrm{~V})$ is low, therefore their oxidative force is not enough to oxidize salicylic acid. Salicylic acid is easily oxidized by chlorine, but this reaction proceeds nonstoichiometrically. Therefore, to quantify phenolic acids, an electrogenerated bromine is chosen as the optimal reagent from all of us studied, which allows the reactions to be carried out quickly and stoichiometrically. Analysis of salicylic acid content in real objects - drugs «Salicylic paste» and "Salicylic ointment» - confirmed the correctness of the choice of electrogenerated bromine as a titrant.

There is no information on the mechanism of interaction of routine with halogens in the literature. We assume that together with the oxidation of hydroxyl groups, an electrophilic substitution reaction in the benzene ring is also possible. We found that rutin does not interact with the electrogenerated $\left[\mathrm{Fe}(\mathrm{CN})_{6}\right]^{3-}$, while with $\mathrm{Cl}_{2}$ the reaction proceeds nonstoichiometrically; and with electrogenated bromine and iodine, the reactions are carried out at a molar ratio of rutin:titrant of $1: 1$ and $1: 2$, respectively. Therefore, to quantify the routine in real objects, it is recommended to use electrogenerated $\mathrm{Br}_{2}$ and $\mathrm{I}_{2}$ as titrants.

In medicinal phenol-containing drugs, ascorbic acid is often contained, as for example, in the "Ascorutin» preparation produced by OJSC «Kiev Vitamin Plant». Ascorbic acid is a potent antioxidant capable of stopping the growth of cancer stem cells. One «Ascorutin» tablet contains ascorbic acid - $0.05 \mathrm{~g}$, routine - $0.05 \mathrm{~g}$ and auxiliary substances (sugar, potato starch, calcium stearate, talc). Therefore, we also studied the interaction of ascorbic acid with electrogenerated titrants and found that it with all titants is easily oxidized to dehydroascorbic acid at a molar ratio of ascorbic acid to titrant of 1:1.

Results of coulometric determination of ascorbic by reaction with electrogenerated titrant are given in Table 1. The correctness of the determination was checked by the «entered - found» method, the number of tests conducted $n=4$, statistical reliability $P=0.95$.
As can be seen from Table 1, it is better to use halogen titants to quantify ascorbic acid, they are more reactive than $\left[\mathrm{Fe}(\mathrm{CN})_{6}\right]^{3-}$ and their use provides very good accuracy. The determination error, for all titrants as a whole, does not exceed $1.8 \%$, and for halogen titrants within $1 \%$.

In living organisms and in dosage forms, the antioxidant properties of phenolic compounds always work in tandem with ascorbic acid, so there is a need to develop a method for determining them in the joint presence. We propose a method of joint determination of rutin and ascorbic acid in the preparation "Ascorutin». $\mathrm{I}_{2}$ and $\mathrm{Br}_{2}$ were used as electrogenerated titrants for «Ascorutin».

Since the main active substances (rutin and ascorbic acid) in the "Ascorutin" tablets differ in solubility, the following procedure can be proposed for quantitative determination. One «Ascorutin» tablet was first treated with ethyl alcohol ( $96 \%$ by weight) and the resulting alcohol extract was titrated with electrogenated bromine and iodine. The titration results are used to calculate the rutin content of the preparation. The results are shown in Table 2 .

Another tablet "Ascorutin" is treated with warm distilled water and the obtained water extract is titrated with electrogenated bromine and iodine. The content of ascorbic acid in the preparation is calculated from the titration results. The results are shown in Table 3.

As shown by the experimental data (Tables 2 and 3), the developed coulometric titration technique with electrogenated bromine and iodine is characterized by good reproducibility of results, expressiveness, accuracy and can be used to determine the routine and ascorbic acid in drugs.

Table 1 Results of coulometric determination ascorbic acid reaction with electrogenerated titrants $(n=4, P=0.95)$

\begin{tabular}{llll}
\hline $\begin{array}{l}\text { Power } \\
\text { generation } \\
\text { titrant }\end{array}$ & $\begin{array}{l}\text { entered } \\
\text { ascorbic acid, }\end{array}$ & $\begin{array}{l}\text { found ascor- } \\
\text { bic acid, } \mu \mathrm{g}\end{array}$ & $S_{\mathrm{r}}, \%$ \\
\hline $\mathrm{Br}_{2}$ & & $182 \pm 4$ & 0.99 \\
$\mathrm{I}_{2}$ & 180 & $179 \pm 3$ & 0.89 \\
$\mathrm{Cl}_{2}$ & & $185 \pm 4$ & 1.07 \\
{$\left[\mathrm{Fe}(\mathrm{CN})_{6}\right]^{3-}$} & & $191 \pm 5$ & 1.8 \\
\hline
\end{tabular}

Hereinafter, $S_{\mathrm{r}}$ is the relative standard deviation.

Table 2 Results of coulometric determination of the routine in «Ascorutin» $(n=4, P=0.95)$

\begin{tabular}{|c|c|c|c|}
\hline $\begin{array}{l}\text { Power } \\
\text { generation } \\
\text { titrant }\end{array}$ & $\begin{array}{l}\text { entered } \\
\text { tablets } \\
\text { «Ascorutin», } \\
\mu \mathrm{g}\end{array}$ & $\begin{array}{l}\text { found } \\
\text { «Ascorutin» } \\
\text { tablets, } \mu \mathrm{g}\end{array}$ & $S_{\mathrm{r}}, \%$ \\
\hline $\begin{array}{l}\mathrm{Br}_{2} \\
\mathrm{I}_{2} \\
\end{array}$ & 300 & $\begin{array}{l}294 \pm 2 \\
289 \pm 4\end{array}$ & $\begin{array}{l}0.99 \\
0.89 \\
\end{array}$ \\
\hline
\end{tabular}

Table 3 Results of coulometric determination of ascorbic acid in «Askorutin» $(n=4, P=0.95)$

\begin{tabular}{llll}
\hline $\begin{array}{l}\text { Power } \\
\text { generation }\end{array}$ & $\begin{array}{l}\text { entered } \\
\text { tablets } \\
\text { titrant }\end{array}$ & $\begin{array}{l}\text { found } \\
\text { «Ascorutin», }\end{array}$ & $\begin{array}{l}\text { "Ascorutin» } \\
\text { tablets, } \mu \mathrm{g}\end{array}$ \\
\hline $\mathrm{Br}_{2}$ & $\mu \mathrm{g}, \%$ \\
$\mathrm{I}_{2}$ & 300 & $295 \pm 3$ & 1.08 \\
\hline
\end{tabular}




\section{Conclusions}

Thus, the coulometric method we have developed using electrogenerated titrants $\left(\mathrm{Cl}_{2}, \mathrm{Br}_{2}\right.$ and $\mathrm{I}_{2}$ and hexacyanoferrate(III)-ions) can be recommended for the determination of salicylic acid, ascorbic acid and rutin in their joint presence in dosage forms. The method is characterized by high reliability, accuracy and expression compared to the Pharmacopoeia method [1], and also eliminates the error of the experiment.

\section{References}

1. Mashkovsky MD, Babayan EA, Oboimakova AN, Bylaev VM, Severtsev VA, lybimov BI, Sokolov SD, Tentsova AI.

Gosudarstvennaya Farmakopeya. Obshchie metody analiza. Lekarstvennoe rastitel'noe syr'yo. [State Pharmacopoeia. General methods of analysis. Medicinal plant raw materials]. Moscow: Medicina; 1990. V. 2. 453 p. Russian.

2. Gruzik TV. Electrochemical determination of the total content of organic acids in wines, wine materials and juices [dissertation]. Krasnodar (Russia): Kuban State University of Technology; 2015. 123 p. 